\title{
Posse atributiva em Libras
}

\section{Attributive possession in Libras}

\section{Posesión atributiva en Libras}

\author{
(iD) José Ishac Brandão El Khouri \\ Universidade Federal do Tocantins (UFT), Palmas, Tocantins, Brasil. \\ E-mail: brandao.ufg@gmail.com \\ iD) Bruno Gonçalves Carneiro \\ Universidade Federal do Tocantins (UFT), Palmas, Tocantins, Brasil. \\ E-mail: brunocarneiro@uft.edu.br \\ iD@Mônica Veloso Borges \\ Universidade Federal de Goiás (UFG), Goiânia, Goiás, Brasil. \\ E-mail: mvborges8@hotmail.com
}

Resumo: Este artigo é um estudo descritivo sobre o sistema de posse atributiva na língua de sinais brasileira, a partir da análise de dados coletados em campo, em vídeos recebidos do aplicativo WhatsApp e de um corpus sobre piadas que circulam entre os surdos. De acordo com a análise de dados, a posse em Libras acontece por meio de (i) pronomes possessivos; (ii) do sinal PRÓPRIO e por (iii) justaposição. No artigo, descrevemos essas estratégias e apresentamos alguns padrões articulatórios e sintáticos relacionados à construção de posse.

Palavras-chave: Posse. Possuidor. Possuído. Libras.

\begin{abstract}
This article is a descriptive study on the attributive possession system in the brazilian sign language, based on the analysis of data collected in the field, in videos received from the WhatsApp and from a corpus of jokes circulating among the deaf. According to the data analysis, possession in Libras occurs through (i) possessive pronoun; (ii) the OWN sign; and (iii) juxtaposition. In the article, we describe these
\end{abstract}


strategies and present some articulatory and syntactic patterns related to the construction of tenure.

Keywords: Possession. Possessor. Possessed. Libras.

Resumen: Este artículo es un estudio descriptivo sobre el sistema de posesión atributiva en lengua de señas brasileña, basado en el análisis de datos recopilados en el campo, en videos recibidos de WhatsApp y de un corpus de chistes que circulan entre los sordos. Según el análisis de datos, la posesión en libras se produce a través de (i) pronombre posesivo; (ii) el seña PROPIO; y (iii) yuxtaposición. En el artículo, describimos estas estrategias y presentamos algunos patrones articulatorios y sintácticos relacionados con la construcción de la posesión.

Palabras clave: Posesión. Poseedor. Poseído. Libras.

Submetido em 10 de julho de 2020.

Aceito em 12 de outubro de 2020.

Publicado em 04 de junho de 2021. 


\section{Introdução}

A posse é um domínio ainda pouco descrito na Libras. Os poucos trabalhos disponíveis fazem uma descrição das formas dos pronomes possessivos nessa língua, sem apresentar outras possibilidades de posse, nem relacionar esse domínio com outras propriedades, como número e alienabilidade (BERENZ, 1996; FELIPE, 2007; FERREIRA, 1995; QUADROS; KARNOPP, 2004). Ainda em relação aos pronomes possessivos, não há detalhes sobre (i) o padrão articulatório, no que se refere à repetição e à duplicação; (ii) o comportamento direcional desses pronomes; (iii) a sua distribuição nas pessoas do discurso; e (iv) a posição dessas formas em relação ao nome possuído.

A posse é um domínio complexo que se manifesta de maneira convencionada em todas as línguas. Do ponto de vista sintático, a posse pode ser expressa de duas maneiras: posse predicativa e posse atributiva, que serão discutidas mais adiante. Neste artigo, atemo-nos apenas à descrição da posse atributiva na Libras, ou seja, à posse dentro de um sintagma nominal.

A partir da manifestação de posse nas línguas de sinais (QUER et al, 2017), partimos da hipótese de que, na Libras, a posse atributiva acontece através do uso de um sistema pronominal, do uso do sinal PRÓPRIO e de justaposição para, assim, estabelecer uma relação entre as entidades possuidor e possuído. Os pronomes possessivos na Libras envolvem diferentes configurações de mão e estão intimamente relacionados às estratégias de indicação das pessoas do discurso. Dessa forma, a dêixis possui uma forte relação com a posse na Libras.

Este artigo apresenta alguns dos resultados de uma pesquisa sobre o sistema de posse na língua de sinais brasileira (EL KHOURI, 2020). O corpus de análise desta pesquisa é composto de (i) dados coletados em campo, através de observações e anotações de conversas espontâneas entre surdos; (ii) mensagens de vídeos re- 
cebidos pelo aplicativo WhatsApp; e (iii) vídeos de um banco de dados intitulado Temáticas recorrentes nas piadas surdas. A coleta de dados aconteceu entre os meses de setembro de 2017 e maio de 2019. Considerando as três fontes de coleta de dados, contamos com a colaboração de 14 participantes surdos/as ( 7 homens e 7 mulheres) das cidades de Porto Nacional-TO, Palmas-TO, Goiânia-GO, Caldas Novas-GO e Imperatriz-MA. Os participantes possuem idade entre 20 e 49 anos, com uma média de 28,5 anos. A quase totalidade dos participantes relata ter experiência por mais de 10 anos como sinalizante da Libras e apenas 1 participante relata ter 7 anos de experiência. A maioria dos participantes são acadêmicos que relatam ter domínio relativo do português e tiveram acesso à Libras tardiamente.

Os dados coletados em campo aconteceram em momentos de interação entre surdos, em situações das mais diversas. Nessas situações reais da língua em uso, as construções de posse eram identificadas. Simultaneamente à coleta de dados em campo, foi realizado um levantamento de dados a partir de vídeos em Libras, recebidos pelo aplicativo WhatsApp. Os vídeos atendiam a propósitos comunicativos dos mais diversos e foram elaborados por surdos adultos, fluentes em Libras.

À medida que as construções de posse eram identificadas, os vídeos eram selecionados e, posteriormente, fizemos contato com os autores do discurso sinalizado. Ressaltamos que os vídeos coletados e analisados tiveram autorização dos participantes, que também permitiram o uso de suas imagens. Os dados em vídeo (provenientes do aplicativo WhatsApp e do corpus de piadas que circulam entre surdos) foram analisados com o auxílio do Software ELAN (Eudico Language Annotator). ${ }^{1}$

Os dados coletados através dessas três fontes foram reanalisados e tratados em um arquivo no Excel para uma tabulação unificada das descrições. No arquivo, listamos um total de 38 construções de posse em Libras, produzidas por 14 participantes surdos diferentes.

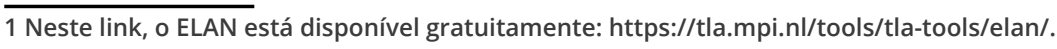




\section{O sistema de posse nas línguas}

A posse é um domínio complexo que está presente em todas as línguas do mundo. Mas, apesar dessa universalidade, o termo 'posse' envolve uma gama de fenômenos linguísticos distintos, diferindo em sua forma e função. Essa especificidade lança desafios para a análise linguística.

De acordo com Baldi e Nuti (2010), Herslund e Baron (2001) e Seiler (2001), a posse pode ser definida como um domínio biocultural oriundo da relação entre um ser humano e seus parentes, partes do seu corpo, seus pertences materiais, seus produtos culturais e intelectuais. Dessa forma, a posse envolve uma relação entre, pelo menos, dois itens linguísticos: uma entidade possuidora e uma entidade possuída. A atribuição desses papéis, possuidor e possuído, é exclusiva e envolve uma relação interessante, pois não há possuidor sem possuído e não há possuído sem possuidor.

Seiler (2001) afirma que posse é uma construção dinâmica cuja relação entre possuidor e possuído está atrelada a uma apropriação progressiva das coisas do mundo e vinculada ao "eu" (EGO). Para ilustrar a dinamicidade, o autor descreve a posse a partir de três perspectivas: distinção, gênese e essência. O esquema 1 a seguir ilustra essa proposta.

Esquema 1 - Possessividade a partir das perspectivas distinção, gênese e essência.

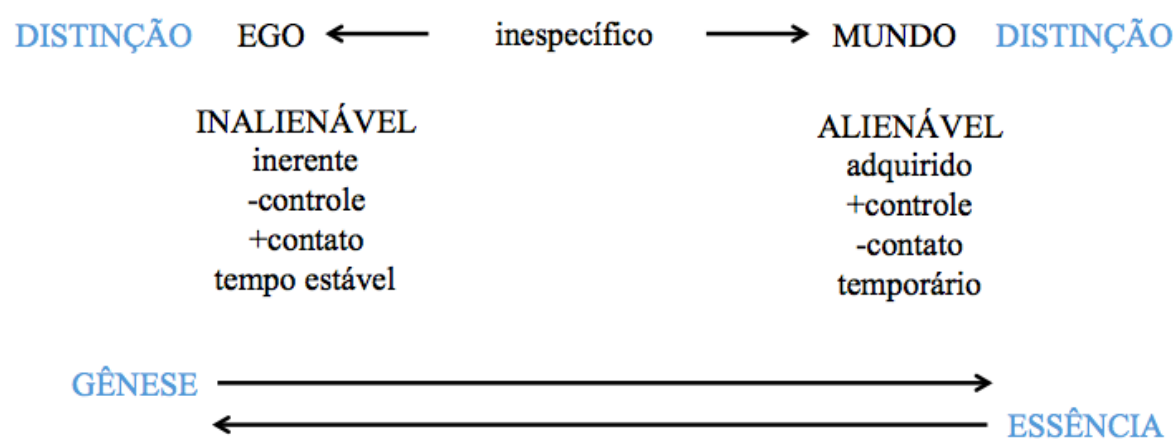

Fonte: Seiler (2001, p. 29) - Adaptado pelos autores. 
De acordo com o esquema, a posse é uma relação entre o EGO e as coisas do mundo externo. O EGO tem um sentido abstrato e se refere, em geral, aos possuidores, sem estar restrito à primeira pessoa do singular. Nessa relação, a dinâmica da posse implica um processo que irradia em duas direções opostas, cada uma em direção ao seu máximo ideal. A partir disso, a relação de posse pode ser interpretada sob três diferentes perspectivas. A primeira perspectiva, DISTINÇÃO, consiste em fazer uma distinção entre inalienável, considerada uma relação de posse inerente, e alienável, uma relação de posse adquirida. Essa distinção acontece através de parâmetros ordenados por implicação: (i) inerente/adquirido; (ii) menos controle/mais controle; (iii) mais contato/menos contato; e (iv) tempo estável/temporário.

A posse inalienável refere-se a uma relação natural, como, por exemplo, a relação entre um ser humano e as partes de seu corpo. Nesse caso, a relação é menos controlada, há mais contato e mais estabilidade. Diferentemente, a posse alienável é uma relação resultado de um processo de aquisição. Aqui, a relação é mais controlada, há menos contato e é temporária.

Outra perspectiva diz respeito à GÊNESE, que marca o ponto de partida e a dinâmica de apropriação crescente. O ponto de partida é considerado a relação de posse mais fácil e, portanto, mais natural, por ser algo inerente às noções relativas ao nosso eu. $\mathrm{A}$ seta no sentido da esquerda para a direita leva-nos a um centro de neutralidade e, posteriormente, à inversão, em direção a um máximo de alienabilidade (e um mínimo de inalienabilidade). Essa seta descola-se para as relações mais distanciadas, levando-nos às noções de "adquirir", "propriedade" e "pertencer", representando a essência da posse.

Porém, mesmo um elemento possuído, que seja considerado adquirido e controlado ao máximo, deve estar sempre relacionado ao possuidor, ou seja, precisa estar voltado para o EGO. Por isso, a seta da ESSÊNCIA está no sentido da direita para a esquerda, simbolizando a perspectiva das aquisições de volta ao ponto de partida, vinculadas ao EGO. As duas linhas cruzadas, em sentidos opos- 
tos, também nos dizem que "inalienabilidade" e "alienabilidade" não são separadas, apesar de distintas. São dimensões que estão ativas em todo o domínio, embora em proporções diferentes, tais como mais "alienabilidade", menos "inalienabilidade" e vice-versa. Ou seja, a distinção é algo gradiente. De alguma forma, toda essa gradação manifesta-se na organização linguística das línguas, de diferentes maneiras.

De um ponto de vista sintático, a posse pode se manifestar de forma predicativa ou de forma atributiva (BALDI; NUTI, 2010; QUER et al, 2017; HERSLUND; BARON, 2001; SEILER, 2001).

A posse predicativa é expressa por um verbo, ou seja, uma unidade predicadora seleciona seus argumentos que, por sua vez, assumem os papéis de possuidor e possuído. No entanto, a posse predicativa é estabelecida apenas em verbos que, de modo específico, estabelecem essa relação. Para isso, temos um verbo transitivo que promove a relação entre duas entidades, através do EGO e da entidade que está sendo adquirida. Seiler (2001) ressalta que algumas expressões podem até implicar uma relação de possessividade enquanto consequência, mas não se configuram em expressão de posse enquanto oriunda do sistema gramatical de posse da língua.

Na maioria das línguas, a posse predicativa é codificada pelo verbo 'ter', através de construções existenciais ou, ainda, de construções locativas. A sentença em (cf. 1) ilustra a posse predicativa no inglês, através do verbo to have, em que o possuidor é o sujeito gramatical do verbo e o possuído é o objeto (BALDI; NUTI, 2010, p. 239).

(1) I have three children Tradução: Eu tenho três crianças Fonte: Baldi e Nuti (2010, p. 239).

20 gradualismo é uma das possibilidades de descrição do fenômeno de posse nas línguas, podendo haver possibilidades alternativas de abordagem, com implicações relevantes para a análise das expressões linguísticas e para a ontologia das categorias. 
A posse atributiva é codificada em um sintagma nominal em que emerge uma relação pressuposta entre possuidor e possuído, sem a mediação de um verbo. Neste sintagma, intitulado de sintagma genitivo, a relação de posse pode acontecer através de justaposição, pronome ou afixo (genitivo). As sentenças em (cf. 2), (cf. 3) e (cf. 4) ilustram uma relação de posse atributiva através de justaposição em hup (STENZEL, 2009), de pronome possessivo em inglês (BALDI; NUTI, 2010) e de afixo em mehináku (STENZEL, 2009), respectivamente.

(2) bú ? toj

Tradução: nariz do tamanduá

tamanduá nariz

Fonte: Stenzel (2009, p. 3).

(3) I have an idea

Tradução: Eu tenho uma ideia

Fonte: Baldi e Nuti (2010, p.239).

(4) nu-hapáya

Tradução: Meu estômago

1sg-estômago

Fonte: Stenzel (2009, p. 2).

Especificamente em relação à posse atributiva, Nichols (1986) estabelece que, na relação entre possuidor e possuído, o nome 'possuído' é considerado o núcleo enquanto o nome 'possuidor' é considerado o dependente. Ou seja, o possuído é o elemento do constituinte que se apresenta como primário, pois é ele quem determina a possibilidade de existência do elemento possuidor (dependente). Ao estabelecer a relação de posse, há línguas que marcam o elemento núcleo (possuído) e línguas que marcam o elemento dependente (possuidor).

Assim, a atribuição dos papéis de possuidor e de possuído pode acontecer através da presença e/ou ausência de marcadores 
de posse, da ordem dos constituintes, de características do sistema pronominal envolvendo o possuidor, bem como por uma combinação dessas e outras possibilidades (BALDI; NUTI, 2010). Uma estrutura possessiva pode ser caracterizada também por possuir marcadores específicos que, formalmente, refletem uma categoria possuidora para diferentes níveis semânticos. Há línguas, por exemplo, que usam marcadores específicos dependendo da relação expressa, se alienável ou inalienável. De acordo com Seiler (2001), uma relação inalienável é considerada uma construção mais antiga, natural e não marcada, enquanto a alienável é mais jovem, derivada e marcada.

A posse predicativa e a posse atributiva também trazem relações semântico-funcionais específicas. De acordo com Baldi e Nuti (2010), a posse predicativa prototípica envolve uma sentença simples, declarativa e traz informações sobre uma posse alienável. Relações óbvias do tipo "Eu tenho uma cabeça", inalienáveis, são consideradas atípicas. Ao contrário, a posse atributiva prototípica envolve tanto as relações alienáveis quanto as relações inalienáveis. Dessa forma, as construções atributivas parecem ser mais abrangentes.

Por fim, os autores ressaltam que o domínio da posse pode ser descrito como uma espécie de constelação de formas, funções e categorias semânticas que estão relacionadas a fenômenos psicológicos e físicos, no nível referencial. Isso porque a posse é consequência de uma generalização nocional oriunda de uma experiência ampla que, por sua vez, é codificada enquanto fenômeno linguístico. Ressaltam ainda que o conteúdo semântico das expressões possessivas prototípicas é centrado em torno do espaço semântico da esfera pessoal e, por extensão, será considerado como uma referência genérica para todo o domínio.

Assim, as línguas apresentam padrões específicos de manifestação, a partir das noções prototípicas de posse. O possuidor, por exemplo, seria uma entidade conhecida, animada (mais especificamente humana) e considerada uma entidade saliente do sin- 
tagma. O possuído seria uma entidade inanimada, concreta e que tem que se relacionar com o possuidor para ser individualizada.

$\mathrm{Na}$ próxima seção, apresentamos um breve panorama da posse atributiva em algumas línguas de sinais, especificamente no que se refere ao uso de pronomes possessivos.

\section{Posse atributiva em línguas de sinais}

De acordo com Quer et al (2017), nas línguas de sinais estudadas até o momento, foram observadas três maneiras de construir a posse atributiva através de: (i) pronomes possessivos; (ii) de um marcador vinculado à posse e (iii) por justaposição.

A relação de posse, a partir dos pronomes possessivos, acontece a partir da dêixis que indica os referentes envolvidos. Assim, nas línguas de sinais, os pronomes possessivos são direcionais, como os pronomes pessoais, mas geralmente apresentam uma configuração de mão diferente destes. Quanto à posição, os pronomes possessivos podem estar prepostos ou pospostos ao referente possuído.

Os pronomes pessoais nas línguas de sinais acontecem através da indicação do referente e, em algumas línguas, estes mesmos sinais podem ser pronomes pessoais/possessivos/demonstrativos, dependendo de contexto. Nestas línguas de sinais, os pronomes possessivos são realizados através do dedo indicador apontando para o referente possuidor. Na língua de sinais Kata Kolok (Indonésia), o apontar é usado para identificar tanto o possuidor quanto o possuído, cuja direção é predominantemente determinada pela localização do referente no mundo real.

Nessa língua de sinais, a posse pronominal alienável e a posse pronominal inalienável são expressas apontando-se para o possuidor. O dado a seguir (cf. 5) ilustra o uso do sinal de indicação para expressar o possuidor, que pode tanto preceder quanto suceder o referente possuído. 
(5)

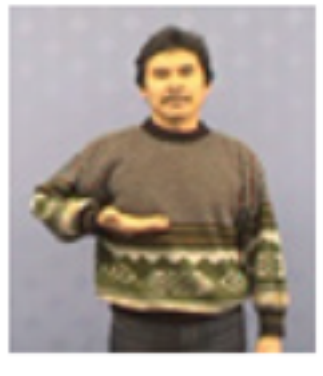

MÃE

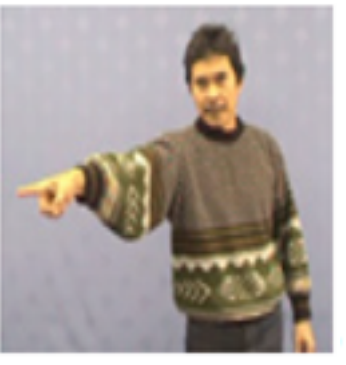

IX (dele/dela)

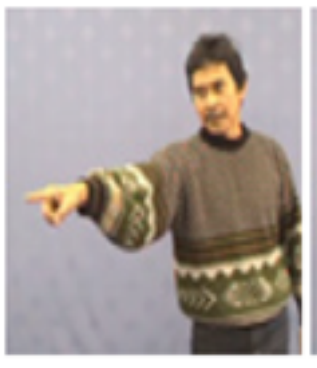

IX (dele/dela)

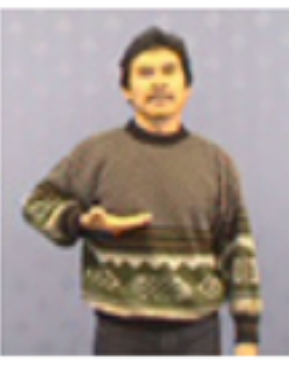

MÃE

Contudo, de acordo com Cormier (2009 apud PFAU; STAINBACK; WOLL, 2012), os pronomes possessivos geralmente têm uma configuração de mão diferente da configuração dos pronomes pessoais, ou seja, diferente do dedo indicador estendido ( mesmo apresentando uma manifestação direcional. Segundo a autora, a configuração de mão em B (\$.\$ ), com a palma voltada para o referente possuidor, é utilizada na língua de sinais americana, na língua de sinais croata, na língua de sinais austríaca, na língua de sinais finlandesa, na língua de sinais dinamarquesa e na língua de sinais de Hong Kong.

Na língua de sinais de Hong Kong, a forma de mão em B ( posse é restrita à posse predicativa. A posse atributiva é expressa via indicador estendido ( A configuração de mão em $B$ também está presente na Libras, embora com uma distribuição restrita à primeira pessoa do singular, conforme será discutido adiante. Os dados a seguir (cf. 6) ilustram os pronomes possessivos com a configuração de mão em B na língua de sinais americana. 
(6)
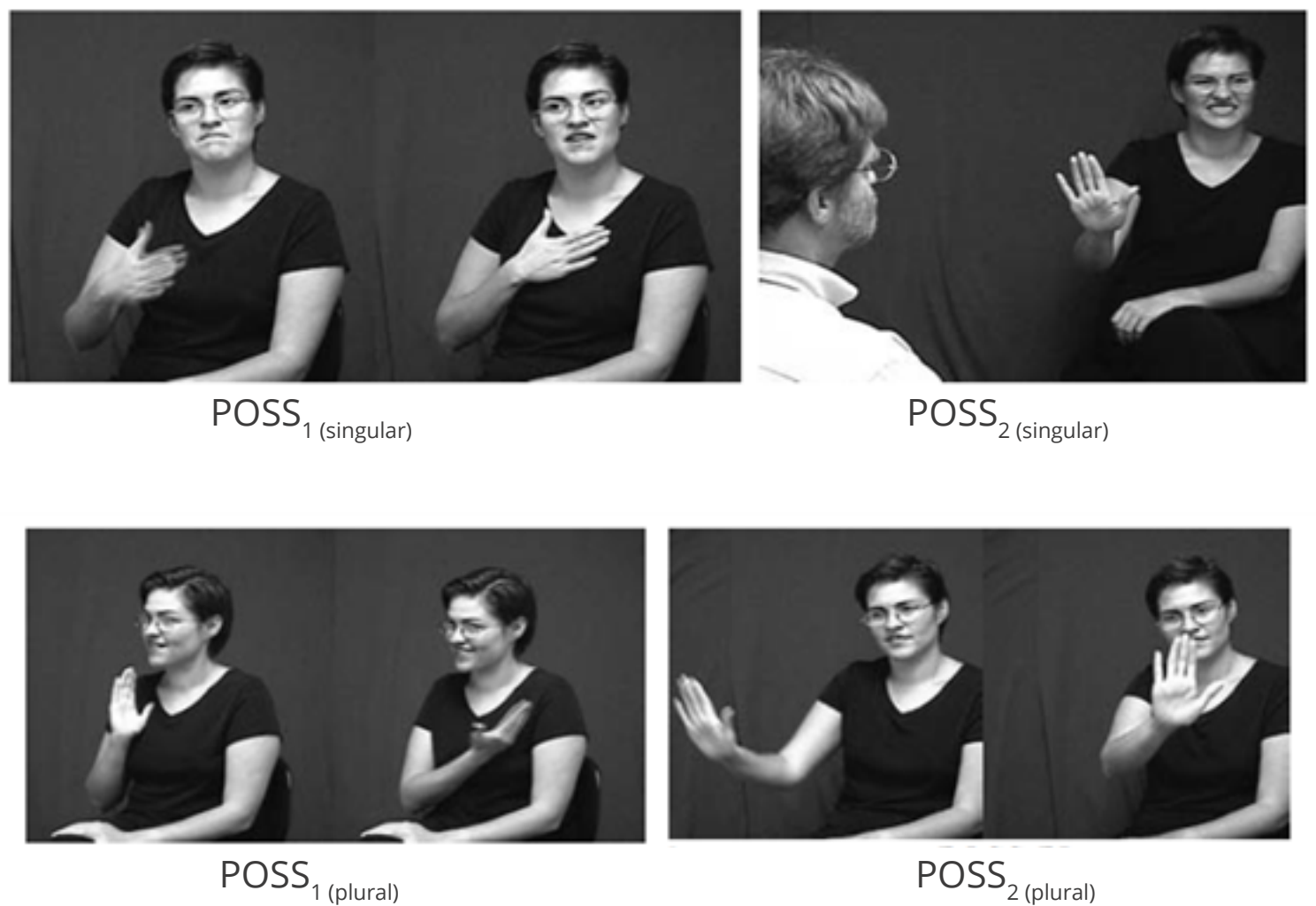

Fonte: Liddell (2003, p. 30 e 31).

De acordo com Liddell (2003), o possessivo de primeira pessoa (singular) acontece com a palma da mão fazendo contato com o peito do sinalizante e normalmente aparece na posição inicial do sintagma. O pronome de não-primeira pessoa possui a mesma configuração de mão, e a palma da mão está voltada para o possuidor. No caso das formas plurais, o pronome possessivo de primeira pessoa (plural) é articulado com um contato inicial no lado ipsilateral do tórax, fazendo um arco de movimento no peito, seguido de um contato no lado oposto do tórax, com o lado ulnar da mão.

O sinalizante também pode se inclinar para a direita, por exemplo, para indicar outros possuidores que estão localizados à direita do sinalizante. Assim, embora a mão do sinalizante não aponte para os outros referentes, o deslocamento do corpo pode, às vezes, realizar o mesmo propósito. Para os referentes de não- 
-primeira pessoa, a palma da mão está voltada para fora e se move em arco a contemplar o grupo de referentes possuidores.

Na língua de sinais australiana, além da configuração de mão em B (․ํ) para indicar posse, há pronomes possessivos com a configuração de mão em $S$ ( ( ) cuja palma da mão também está voltada para o referente possuidor (JOHSTON; SCHEMBRI, 2006). Na língua de sinais indo-paquistanesa (IPSL), segundo Zeshan (2003), além da configuração de mão com o dedo indicador estendido ( como pronome possessivo, há uma forma com a configuração de mão em A e com a configuração de mão ilustrada a seguir (cf. 7), que são usadas para enfatizar a posse. A autora ressalta que essas duas formas enfáticas são pouco frequentes.

(7)

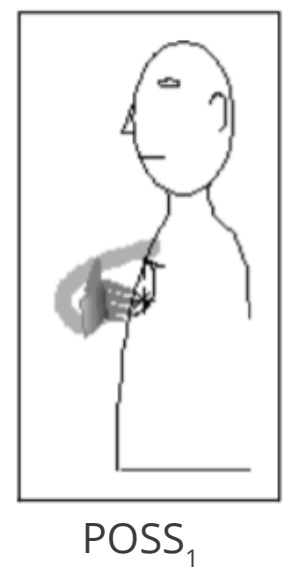

Tradução: Meu (enfático) Fonte: Zeshan (2003, p. 180).

O marcador vinculado à posse diz respeito a sinais, presentes em algumas línguas sinalizadas, que estabelecem uma relação entre um possuidor e um possuído. Na língua de sinais australiana, há um sinal que parece ter sido emprestado do inglês por meio da grafia e assemelha-se ao morfema de posse expresso pelo grafema "s", como em mother's house (casa da mãe). Essa forma, ilustrada a seguir (cf. 8), é usada para indicar posse na língua de sinais australiana, particularmente quando se discute relações familiares (JOHNSTON; SCHEMBRI, 2006). 
(8)

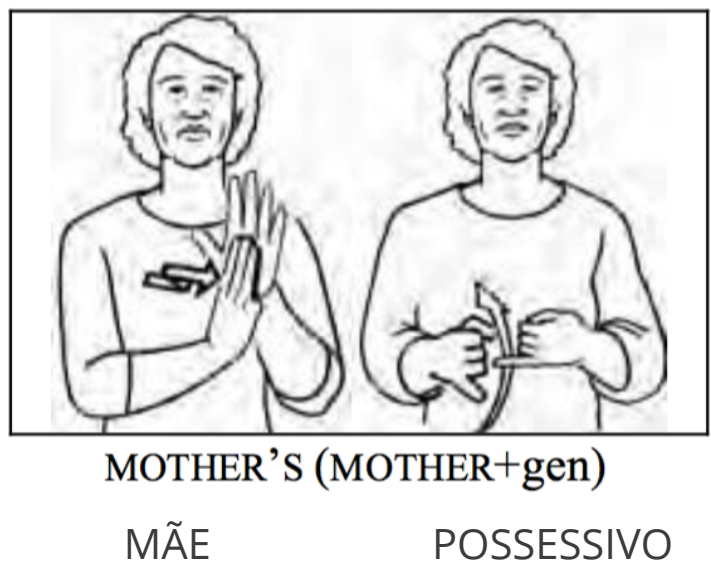

Fonte: Johston e Schembri (2006, p. 129).

A justaposição é uma estratégia de posse simples, pois não envolve marcação morfossintática adicional. Nesta estratégia, possuído e possuidor são articulados de maneira sequencial. $\mathrm{Na}$ língua de sinais indo-paquistanesa, a posse por justaposição é idêntica a outras construções modificadoras na língua, que também são realizadas por justaposição. Na IPSL, o possuidor sempre precede o possuído, de acordo com um princípio mais geral da língua, em que os modificadores precedem os itens modificados (ZESHAN, 2003).

Ainda segundo Quer et al (2017), uma estratégia alternativa para a construção de posse é o uso do espaço de sinalização (justaposição espacial). Nas línguas de sinais, o uso produtivo do espaço com a articulação de um referente possuído, em um mesmo local em que previamente havia sido articulado um referente possuidor, numa espécie de empilhamento, pode promover a ideia de posse. Esse uso produtivo do espaço pode ser categorizado dentro da estratégia de justaposição. O dado a seguir (cf. 9) ilustra essa relação na Libras. 
(9)

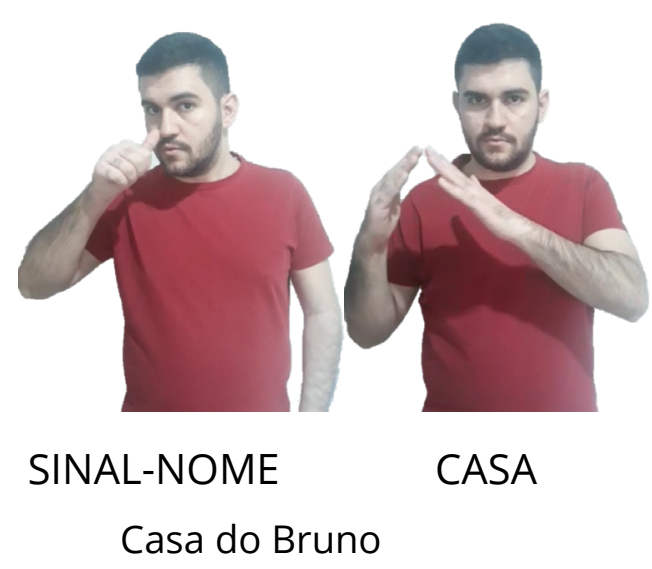

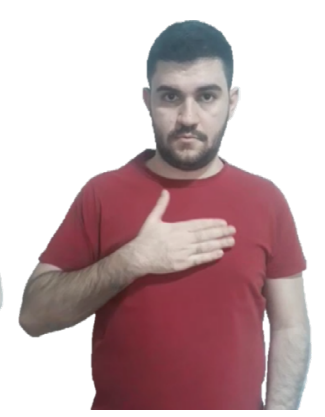

POSS,

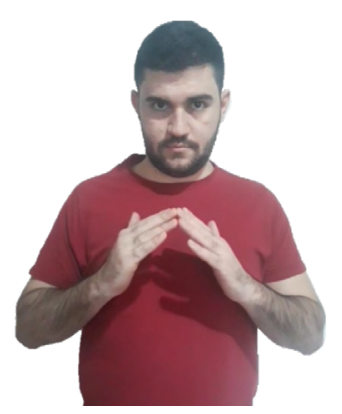

CASA

Minha casa
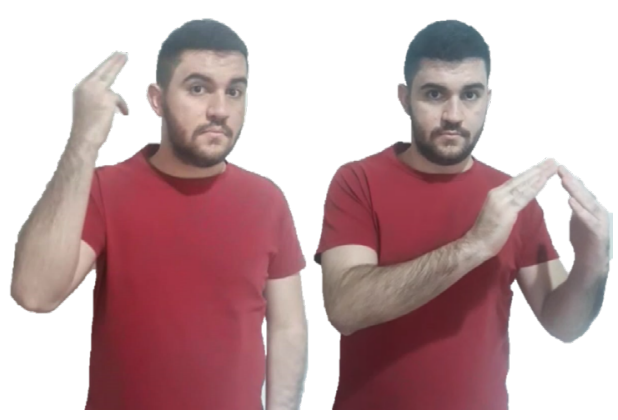

SINAL-NOME

CASA

Casa da Mônica

Fonte: Elaborada pelos autores.

Ressaltamos que cada língua de sinais, enquanto línguas individuais, possui uma organização específica em relação ao sistema de posse. Dessa maneira, há diferenças tipológicas entre as línguas de sinais. Na próxima seção, apresentamos a posse atributiva em Libras a partir dos resultados da pesquisa.

\section{O sistema de posse atributiva na Libras}

Conforme mencionado na introdução deste artigo, nesta pesquisa identificamos 38 construções de posse, considerando as três 
fontes de dados (em campo, em vídeo de WhatsApp e no banco de dados de piadas contadas por surdos).

Dessa maneira, das 38 construções de posse, categorizamos 29 através do uso de pronomes possessivos, nas três pessoas do discurso, singular e plural; 5 construções de posse através do sinal PRÓPRIO e 4 construções de posse através de justaposição. Essas estratégias são discutidas nesta seção.

\section{Posse por pronomes possessivos}

Em relação ao uso de pronome possessivo como estratégia de posse, foram observados três sinais que apresentam uma distribuição distinta em relação às pessoas do discurso: (i) pronome possessivo com a configuração de mão em $B$; (ii) pronome possessivo com a configuração de mão em P; e (iii) pronome possessivo com a configuração de mão em que apenas o dedo indicador está estendido, aqui glosado em IX. Grosso modo, a configuração de mão em IX corresponde à indicação através do dedo indicador. Nesta pesquisa, conforme será apresentado mais adiante, esta categoria envolveu outras configurações que, de alguma forma, indicavam o possuidor através de um apontamento, com exceção da configuração de mão em $P$ e em $B$ (através da palma da mão).

Os pronomes possessivos na Libras possuem um comportamento direcional, assim como os sinais de apontamento e os verbos de indicação (LIDDELL, 2003). De acordo com Liddell (2003), há uma cisão entre elementos gestuais e sinais de apontamento e verbos de indicação, de forma a justificar o movimento direcional desses sinais no espaço de sinalização. O grande número de pontos no espaço de sinalização, atribuídos a diferentes referentes, é acessado de maneira produtiva através dessa mescla entre elementos lexicais e gestuais.

O comportamento direcional dos pronomes possessivos indica o referente possuidor. O pronome possessivo com a configuração de mão em $B$ indica o possuidor através da orientação da 
palma. Como esta forma está relacionada apenas à primeira pessoa, a palma da mão está voltada ao sinalizante, tocando a região do tórax. O pronome possessivo com a configuração de mão em $\mathrm{P}$ indica o possuidor através de uma rotação de punho, no sentido de medial para lateral, de maneira que o dedo médio da configuração de mão em $\mathrm{P}$ indica o possuidor. Essa estratégia refere-se ao possuidor de não-primeira pessoa. No caso do possuidor ser a primeira pessoa, a ponta do dedo médio (da configuração de mão em P) toca a região do tórax do sinalizante. Por fim, o pronome possessivo com a configuração de mão em IX indica o possuidor através da direção da ponta do(s) dedo(s), semelhante aos pronomes pessoais.

O uso do pronome possessivo com a configuração de mão em B está relacionado apenas à primeira pessoa do singular. Esta forma não foi encontrada para a segunda e a terceira pessoas do singular, tampouco para a primeira, a segunda e a terceira pessoas do plural. Nesse sentido, o pronome possessivo com a configuração de mão em $B$ apresenta uma distribuição restrita. $O$ dado a seguir (cf. 10) ilustra esse pronome.

\section{(10)}

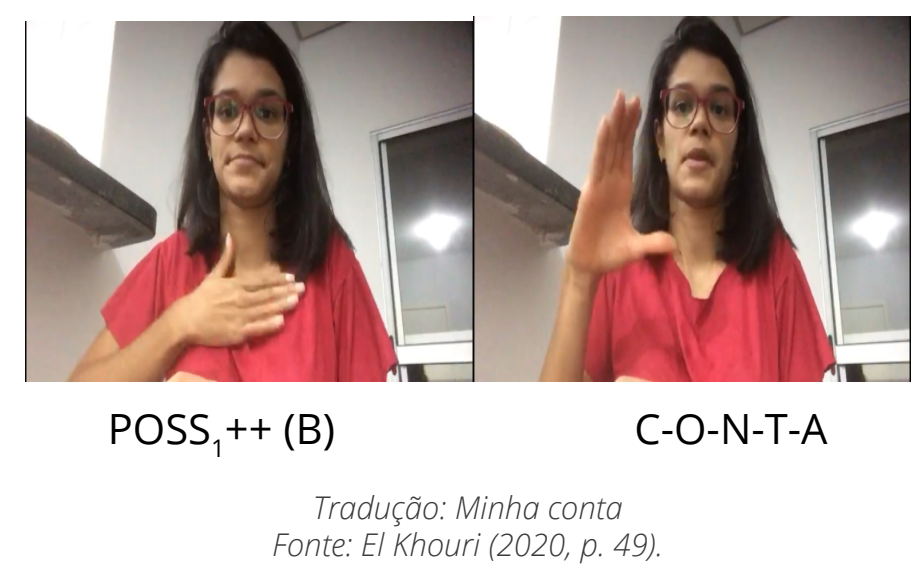

O pronome possessivo com a configuração de mão em B pode ser duplicado, por um processo de assimilação. Ou seja, o pronome possessivo pode ser articulado de maneira bimanual, em que ambas as mãos configuram o pronome simultaneamente. Nos da- 
dos, tais ocorrências foram observadas apenas quando havia um sinal bimanual (referente possuído) no sintagma genitivo, o que sugere um processo de assimilação desse padrão bimanual. Dessa forma, não foi observada uma duplicação proveniente de variação livre (sem assimilação). Ou seja, não foi observado o uso de ambas as mãos na articulação do pronome, sem a presença de um sinal bimanual no sintagma genitivo. Em relação à repetição de movimento, observamos formas repetidas bem como formas sem repetição, com prevalência de repetição de movimento. Em relação à posição do pronome, foram observados pronomes prepostos e pronomes pospostos em relação ao referente possuído, em uma frequência equivalente.

Os pronomes com a configuração de mão em $\mathrm{P}$ e em IX apresentam uma distribuição mais ampla. A configuração de mão em $P$ foi encontrada em primeira pessoa do singular, em segunda pessoa do singular, em terceira pessoa do singular e em segunda pessoa do plural. Em nossos dados, não foram encontradas a primeira pessoa do plural e a terceira pessoa do plural para essa forma. O dado a seguir (cf. 11) ilustra o uso do pronome possessivo com a configuração em $\mathrm{P}$, fazendo referência à primeira pessoa do singular, de maneira duplicada, ou seja, com o uso das duas mãos, e com repetição de movimento.

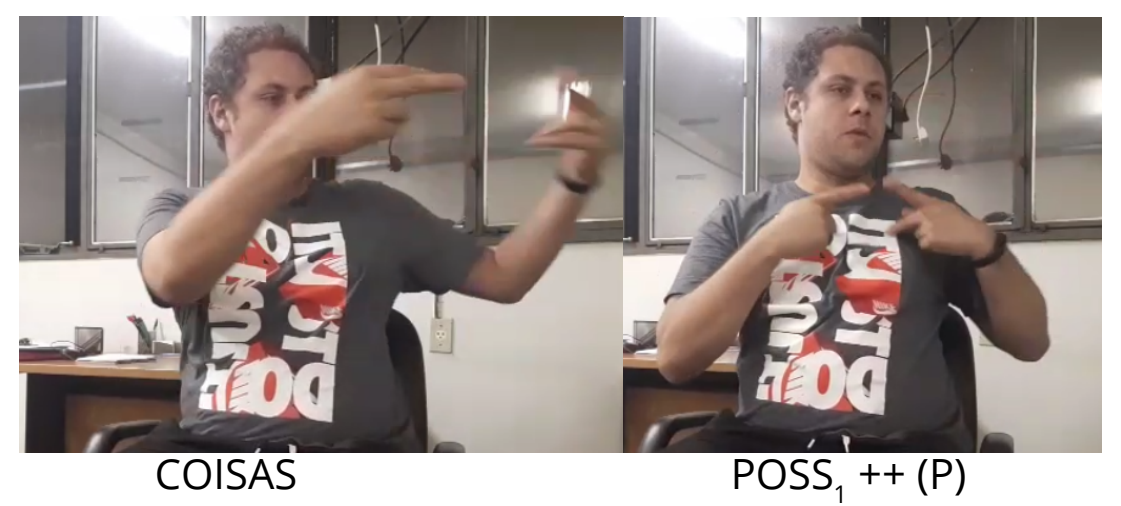

Tradução: Minhas coisas (As coisas são minhas). Fonte: El Khouri (2020, p. 54). 
O dado seguinte (cf. 12) ilustra o uso do pronome possessivo com a configuração de mão em $\mathrm{P}$, fazendo referência à segunda pessoa do plural, através de reduplicação do pronome, sem repetição de movimento e com deslocamento no espaço de sinalização. Ou seja, o pronome possessivo é articulado em um local específico no espaço de sinalização, com o movimento de rotação do antebraço realizado apenas uma vez. Em seguida, há o deslocamento da mão para um novo local no espaço de sinalização e novo movimento de rotação do antebraço (novamente, sem repetição de movimento).

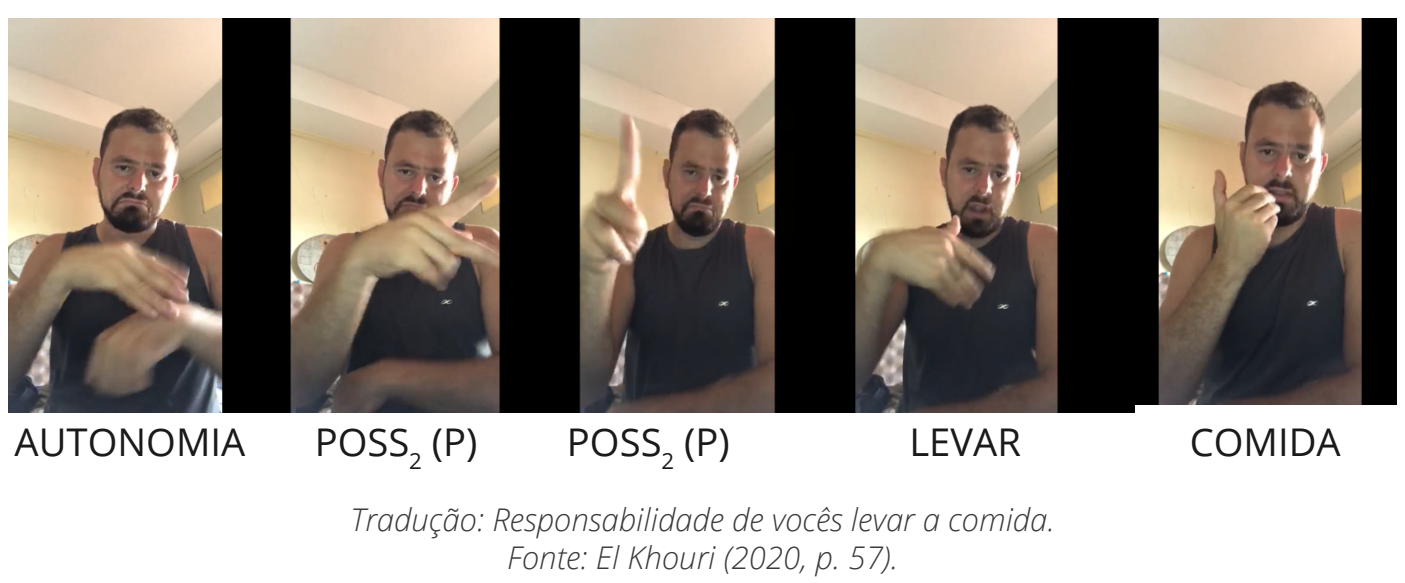

O pronome possessivo com a configuração de mão em P apresentou variação no que se refere à repetição de movimento, ao número de mãos (realizado apenas com uma mão ou com ambas as mãos) e à sua posição em relação ao referente possuído. Houve prevalência de articulação do pronome sem repetição de movimento, de maneira monomanual (apenas com uma mão) e posposto ao referente possuído. No caso de possuidor plural no sintagma genitivo, o pronome foi articulado de maneira reduplicada, com deslocamento no espaço de sinalização e sem repetição de movimento nas formas reduplicadas.

A configuração de mão em IX foi encontrada em primeira pessoa do singular, segunda pessoa do singular, em terceira pessoa 
do singular e em primeira pessoa do plural. Não foi encontrada, em nossos dados, a manifestação da forma IX em segunda e terceira pessoas do plural. Esta configuração apresenta uma distribuição mais ampla (além de uma frequência maior) que as construções de posse envolvendo a configuração de mão em B e em P.

Nesta categoria, consideramos as configurações de mão em que (i) o indicador está estendido e os demais dedos fletidos; (ii) os dedos indicador e médio estão estendidos e os demais dedos fletidos; e (iii) outras configurações de mão que, de alguma forma, indicavam o referente possuidor na construção possessiva, com exceção da configuração de mão em $\mathrm{P}$ e da configuração de mão em B (com a palma da mão orientada para o referente possuidor). O dado a seguir (cf. 13) ilustra o pronome possessivo com (i) o dedo indicador estendido e demais dedos fletidos.

(13)

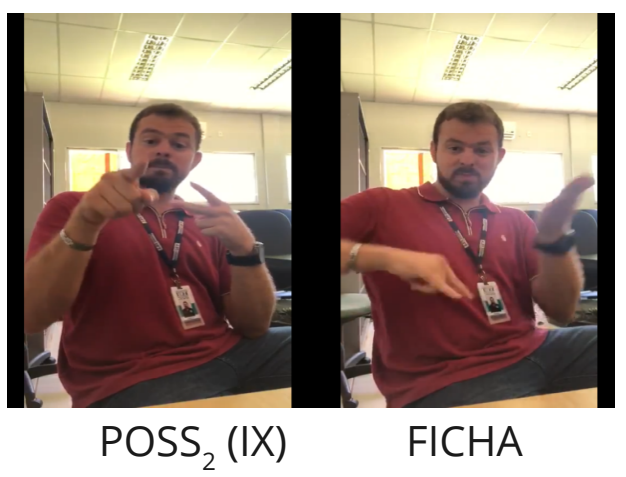

Tradução: Sua ficha. Fonte: El Khouri (2020, p. 65).

O dado a seguir (cf. 14) ilustra a construção de posse com configuração de mão em IX, fazendo referência à primeira e à terceira pessoa do singular, oriundo de provável assimilação. O dado foi coletado no momento de aula na Universidade Federal do Tocantins (UFT). Duas discentes surdas estavam em sala com seus respectivos notebooks sobre a mesma mesa. Em um tom de cordialidade e brincadeira, alguém provocou as alunas com a pergunta "os dois notebooks são gêmeos?". Uma das alunas respondeu conforme a seguinte sentença: 
(14)

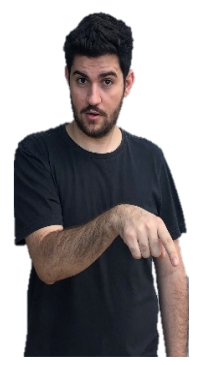

IX (DEM)

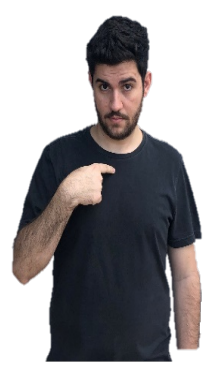

POSS $_{1}(\mathrm{IX})$

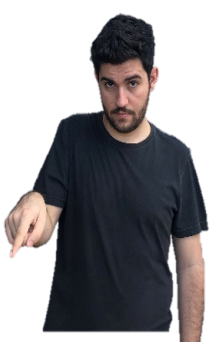

IX (DEM)

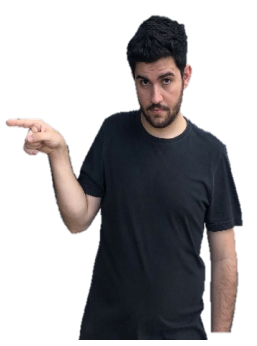

$\mathrm{POSS}_{3}(\mathrm{IX})$

Tradução: Este é meu. Este é dela. Fonte: El Khouri (2020, p. 67).

Neste dado, observa-se que a sinalizante articula o sinal IX como um pronome demonstrativo, de forma a indicar o primeiro notebook como possuído e, em seguida, articula o sinal POSS, com configuração em IX, para indicar o possuidor (primeira pessoa do singular). A sentença continua com a sinalizante articulando o sinal IX direcionado para o segundo notebook (possuído) e articula o sinal POSS $3^{\prime}$ com configuração em IX, para indicar a outra interlocutora como possuidora. Percebe-se que todos os sinais são articulados com a mesma configuração de mão. Dessa maneira, nesta sentença, os pronomes possessivos possuem a mesma configuração que os demonstrativos, provavelmente oriundos de um processo de assimilação.

De acordo com Gabas-Júnior (2000), a assimilação corresponde a uma situação em que características de um segmento condicionam características de outro segmento, próximos um do outro, na cadeia de fala. Na ASL, Liddell e Johnson (1989) mencionam casos de assimilação tanto do traço duplicação das mãos quanto do traço configuração de mão, por um sinal adjacente. Nesse sentido, sugerimos que a forma pronominal possessiva foi configurada em IX (dedo indicador estendido e demais dedos fletidos) por assimilação da forma do pronome demonstrativo.

O dado seguinte (cf. 15) ilustra a construção de posse com configuração de mão em IX, fazendo referência à primeira pessoa do plural. Há a articulação do sinal POSS1 pl, em que a configura- 
ção de mão em IX está com a ponta do dedo indicador direcionado para cima e realiza um movimento de semi-círculo. Neste caso, o possuidor é um referente plural.

\section{(15)}

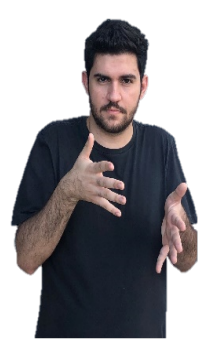

LIBRAS

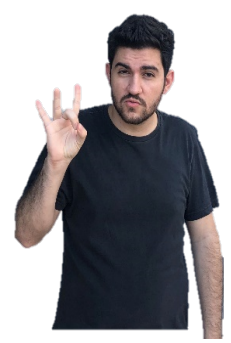

Só

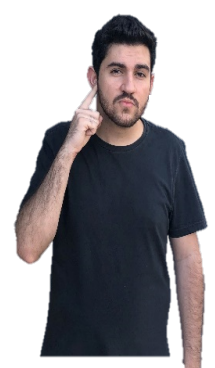

SURDO

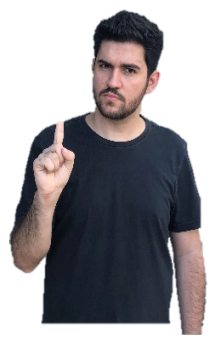

NÃO

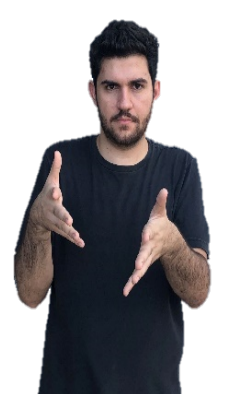

LIBRAS

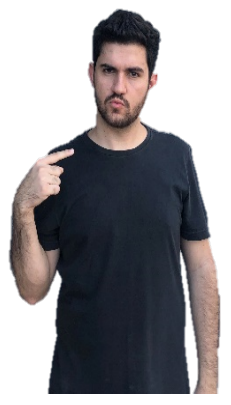

$\mathrm{POSS}_{1} \mathrm{pl}(\mathrm{IX})($ nosso)

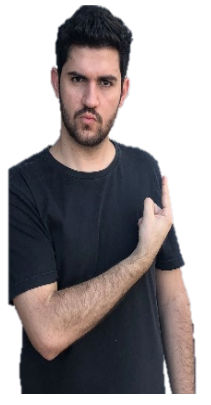

Tradução: A Libras não é só dos surdos. A Libras é nossa. Fonte: El Khouri (2020, p. 68).

O dado a seguir (cf. 16) também ilustra a construção de posse com configuração de mão em IX, fazendo referência à primeira pessoa do plural. A mão está configurada com os dedos indicador e médio estendidos e demais dedos fechados e realiza um movimento no plano horizontal, de maneira a indicar o sinalizante (primeira pessoa) e o espaço de sinalização à direita do quadrante (terceira pessoa). 
(16)

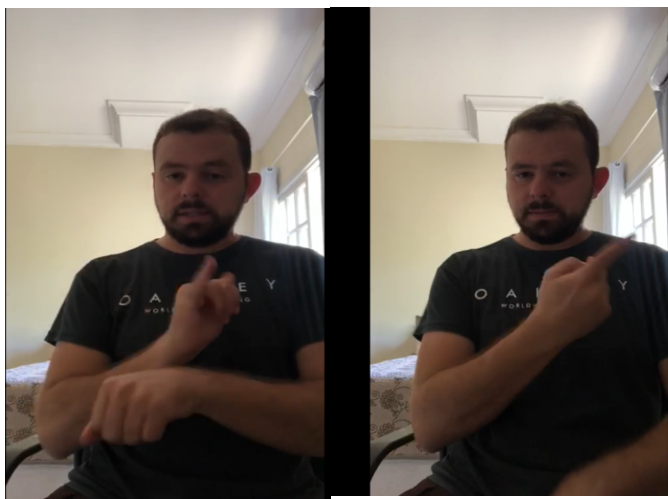

ESTRATÉGIA POSS ${ }_{1 \mathrm{PL}}$ (IX) (nós dois)

Tradução: Nossa estratégia.

Fonte: El Khouri (2020, p. 69).

O pronome possessivo com a configuração de mão em IX não apresentou variação em relação à repetição e em relação ao número de mãos. Ou seja, todas as ocorrências foram articuladas sem repetição de movimento e de maneira monomanual (sem duplicação). Houve sinais articulados tanto prepostos quanto pospostos ao referente possuído.

Conforme mencionado, os pronomes possessivos com as configurações de mão em B, P e IX apresentaram uma distribuição distinta em relação às pessoas do discurso. $O$ esquema 2, a seguir, ilustra essa distribuição:

Esquema 2 - Distribuição dos pronomes possessivos B, P e IX em relação à primeira, segunda e terceira pessoas, singular e plural.

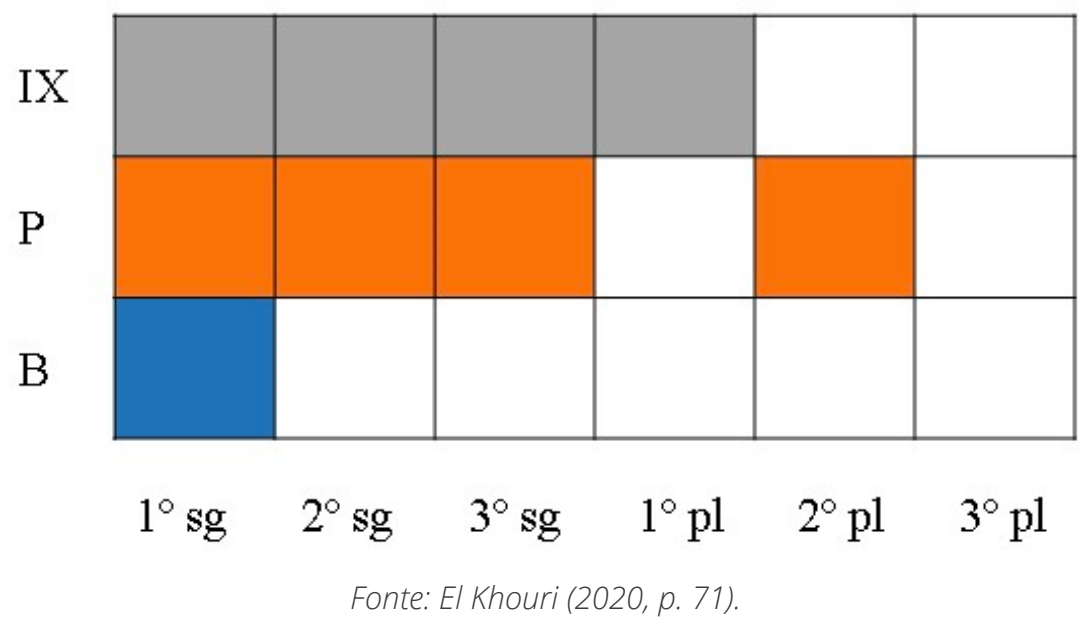


Nesta pesquisa, sugerimos que o pronome possessivo com a configuração de mão em IX possui uma distribuição mais ampla, seguida da configuração de mão em P. O pronome possessivo com a configuração de mão em B possui uma distribuição restrita, abrangendo apenas a primeira pessoa do singular. Mesmo com a limitação do corpus, acreditamos que a forma em $\mathrm{P}$ não é usada para representar a primeira pessoa do plural. Consideramos a necessidade de uma análise maior dos dados, para cobrir uma distribuição em relação às três formas disponíveis dos pronomes possessivos na Libras.

De maneira geral, os pronomes possessivos em Libras parecem ter um padrão de articulação monomanual. As ocorrências de um padrão bimanual (duplicação) foram provenientes de assimilação. Ou seja, nos dados, a articulação do pronome com as duas mãos foi observada apenas quando havia um sinal bimanual (neste caso, o referente possuído), no sintagma genitivo.

O fenômeno da duplicação acontece quando sinais, canonicamente articulados com apenas uma mão, são articulados com as duas mãos. A duplicação das mãos na Libras está relacionada ao plural de argumentos, plural de eventos e intensidade (SANCHEZ-MENDES; XAVIER, 2016; SANCHEZ-MENDES; SEGALA; XAVIER, 2017). Por isso, ressaltamos a necessidade de se verificar se o efeito da duplicação de mãos está relacionado à intensidade de posse ou à variação articulatória sem consequências no significado.

Sobre a posição do pronome em relação ao referente possuído, os dados apresentaram construções com os pronomes tanto prepostos (POSS + POSSUÍDO) quanto pospostos (POSSUÍDO + POSS). Na maioria das construções, o pronome foi articulado após o referente possuído. ${ }^{3}$

Os pronomes possessivos com a configuração de mão em $B$ e com a configuração de mão em $P$ foram articulados, na maioria das construções, com repetição, atingindo $80 \%$ e $87,5 \%$ dos dados, respectivamente. Em relação ao pronome possessivo com a confi-

3 Nesta pesquisa, não estivemos atentos se a construções analisadas eram declarações simples ou sentenças topicalizadas, o que pode influenciar na posição do pronome possessivo. 
guração de mão em IX, todas as manifestações aconteceram sem repetição do sinal.

\section{Posse através do sinal PRÓPRIO}

O sinal PRÓPRIO na Libras é um item lexical relacionado à posse, pois estabelece uma relação entre um referente possuidor e um referente possuído. O sinal PRÓPRIO é bimanual e assimétrico: a mão dominante está configurada em P e faz um deslocamento no plano horizontal, no sentido de lateral para medial, fazendo contato com a mão não dominante. A mão não dominante está aberta, com a palma voltada para medial e dedos estendidos. $\mathrm{O}$ contato é realizado entre região radial da mão dominante com a palma da mão não dominante. O sinal é articulado sem repetição.

O sinal PRÓPRIO não é considerado um pronome, porque ele não substitui o nome, ou seja, não promove apagamento do possuidor. Em nossa análise, tanto o referente possuidor quanto o referente possuído foram articulados nas sentenças. E, em quatro delas (de um total de cinco sentenças), o sinal PRÓPRIO está posposto ao referente possuído e preposto ao referente possuidor. $O$ dado a seguir (cf. 17) ilustra esse padrão.

\section{(17)}

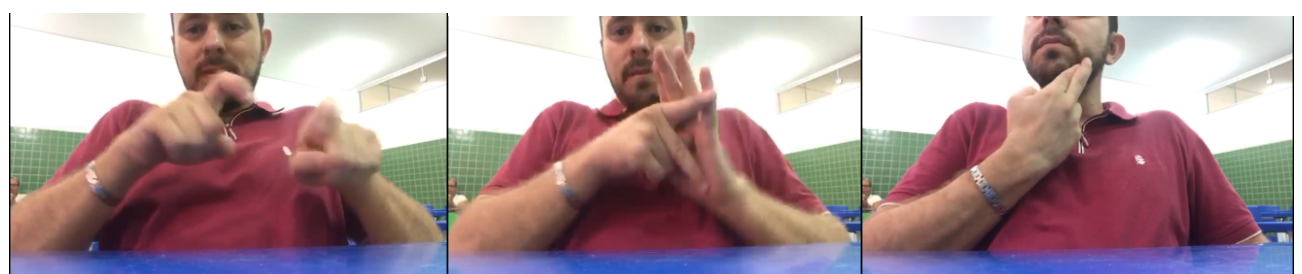

COMPUTADOR

PRÓPRIO

SINAL-NOME

Tradução: Computador do Robinson.

Fonte: El Khouri (2020, p. 74).

Nos dados, o sinal PRÓPRIO também foi articulado posposto à justaposição entre o referente possuído e o referente possuidor (indicado por IX). Neste caso, o sinal PRÓPRIO foi articulado após 
a relação estabelecida pelo pronome. Ressaltamos que o uso do sinal PRÓPRIO junto a pronomes possessivos é uma possibilidade bastante recorrente na Libras, apesar de termos encontrado apenas uma ocorrência em nossos dados. Os exemplos a seguir (cf. 18), (cf. 19), (cf. 20) e (cf. 21) fazem referência a essas construções.

(18)

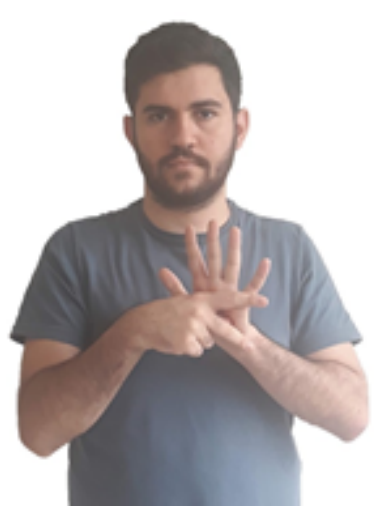

PRÓPRIO

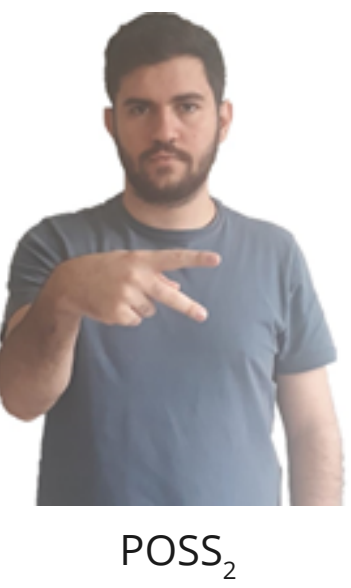

Tradução: (próprio) dele. Fonte: El Khouri (2020, p. 96).

(19)

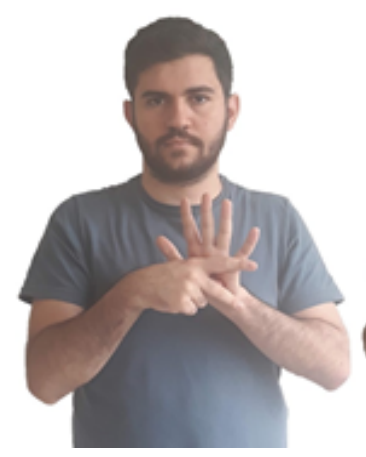

PRÓPRIO

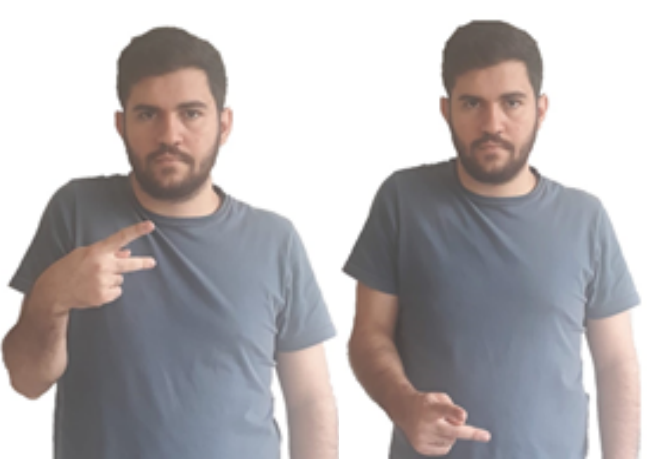

$\mathrm{POSS}_{3}$

Tradução: (próprio) daqui. Fonte: El Khouri (2020, p. 97). 
(20)

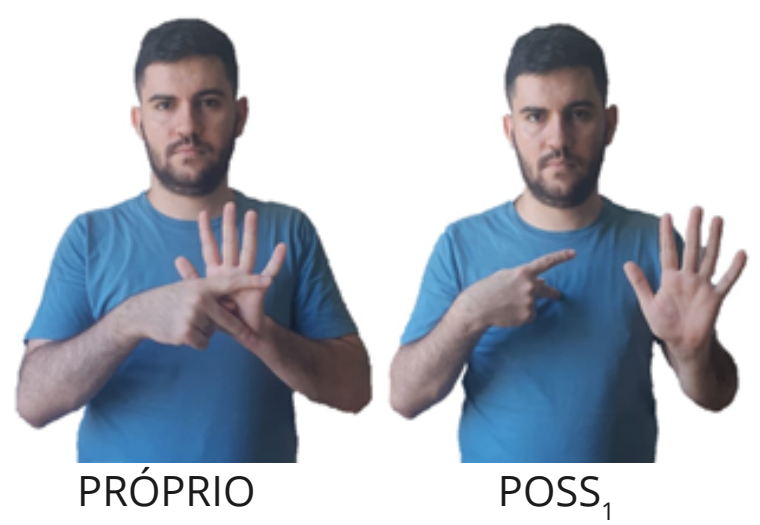

Tradução: (próprio) meu. Fonte: El Khouri (2020, p. 97).

$(21)$

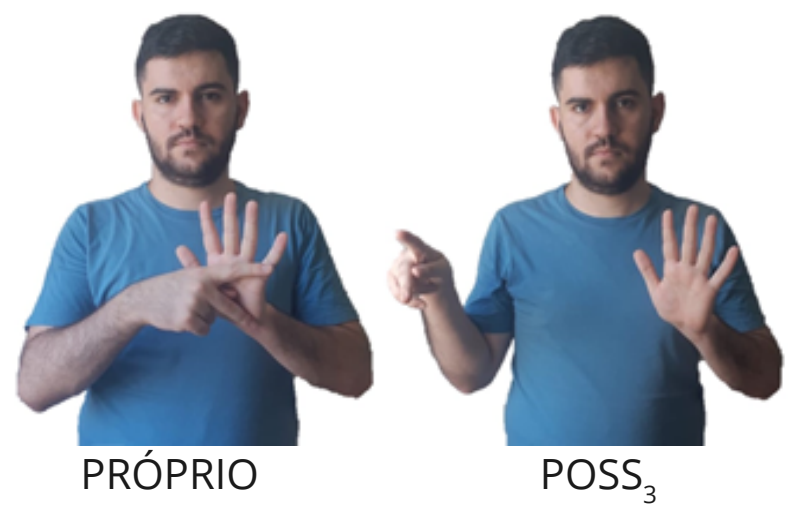

Tradução: (próprio) dele. Fonte: El Khouri (2020, p. 97).

É preciso uma investigação mais específica sobre a semântica do sinal PRÓPRIO em relação à posse, a fim de desvendar instâncias de seu contexto de uso.

\section{Posse por justaposição}

A posse por justaposição é uma estratégia disponível em muitas línguas de sinais (QUER et al, 2017). Nesse sentido, estivemos atentos para a relação estabelecida entre possuidor e possuído por justaposição. 
A identificação de posse por justaposição, em nosso corpus de análise, aconteceu a partir do princípio comum às construções possessivas, estabelecido por Seiler (2001). Segundo o autor, a posse é uma relação entre um elemento possuidor, conhecido e prototipicamente animado (mais especificamente humano), com um elemento saliente e considerado o tópico do sintagma. Nesse sentido, guiamo-nos principalmente na animacidade do elemento possuído, de forma que desconsideramos as relações em que o elemento modificador não apresentasse traços de animacidade.

Essa estratégia é caracterizada pela justaposição do referente possuído e do referente possuidor. Neste caso, o item lexical que codifica o referente possuído e o item lexical que codifica o elemento possuidor são articulados de maneira sequencial.

Os constituintes de uma língua são formados por um elemento núcleo e por elementos dependentes. O núcleo é o elemento do constituinte que se apresenta como primário, pois é ele quem determina a possibilidade de existência dos elementos dependentes. De acordo com Nichols (1986), conforme mencionado anteriormente, o possuído é considerado o elemento núcleo, que é modificado por um elemento dependente, o possuidor. Em todas as construções de posse por justaposição, em nosso corpus de análise, o elemento possuído esteve preposto ao elemento possuidor. Ou seja, o referente possuidor é articulado após o possuído. $O$ dado a seguir (cf. 22) ilustra a estratégia de posse por justaposição ao estabelecer uma relação entre CASA (possuído) e VOV@ (possuidor).

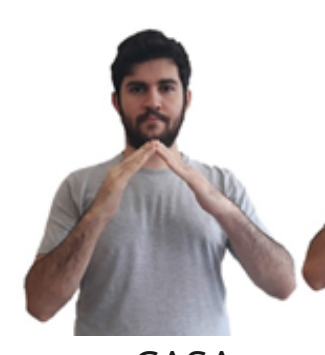

CASA

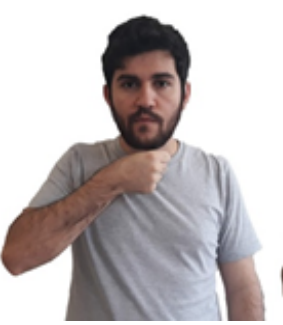

VOV@

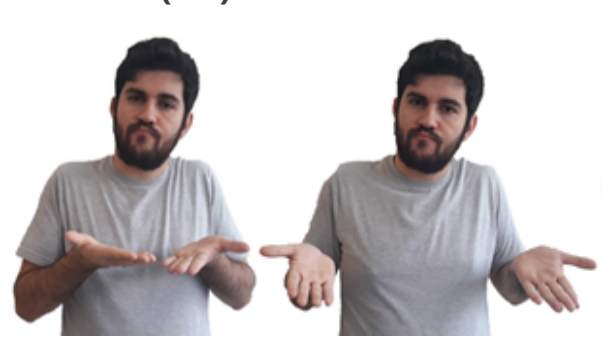

DEM

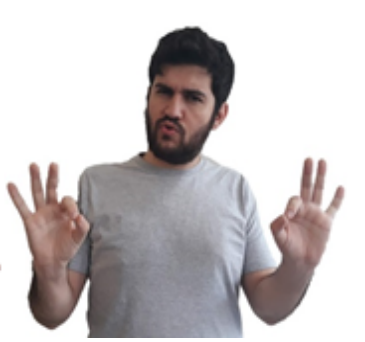

CHIQUE

Tradução: Na casa de vov@, a mesa é chique. Fonte: El Khouri (2020, p. 80). 
Durante a análise de dados, conforme mencionado, deparamo-nos com a estratégia de justaposição que foi desconsiderada como posse, pois não atendia ao critério de animacidade do possuidor (SEILER, 2001). Situações assim foram consideradas relações entre um elemento modificado e um elemento modificador, e não uma relação de posse, como mostra o dado a seguir (cf. 23).

\section{(23)}
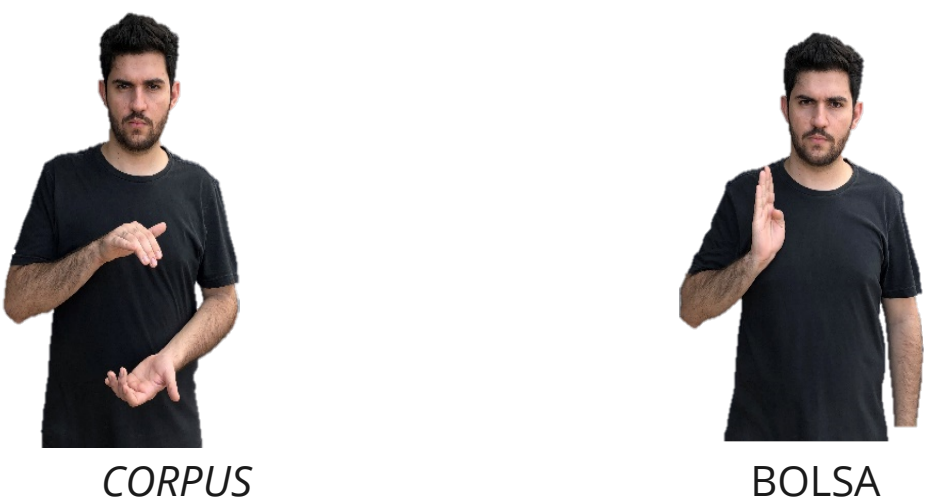

Tradução: Bolsa do Corpus. Fonte: El Khouri (2020, p. 97).

Em (23), o sintagma BOLSA é o elemento modificado, enquanto o sintagma CORPUS é o elemento modificador. A justaposição implica que o sinal CORPUS seja um atributo do elemento BOLSA.

Todos os dados presentes em nosso corpus de análise dizem respeito a construções alienáveis, ou seja, entidades cuja relação de posse com um possuidor pode ser adquirida e/ou desfeita. Nos dados, não encontramos construções inalienáveis, em que essa relação não pode ser desfeita como, por exemplo, a nossa relação com partes do nosso corpo. Da mesma forma, os dados não nos permitiram contrastar construções de posse com possuído animado versus inanimado para verificarmos possíveis estratégias gramaticais específicas. 


\section{Considerações finais}

A língua de sinais brasileira, como língua natural, apresenta estratégias léxico-gramaticais que possibilitam aos seus usuários o envolvimento com o mundo nas mais diversas facetas do comportamento humano, dentre elas a construção de posse.

Conforme mencionado, a posse é um domínio complexo que surge a partir de uma relação entre uma entidade possuidora e outra entidade possuída, envolvendo domínios biológicos e culturais. Este artigo buscou detalhar como acontece essa relação na Libras, especificamente no sintagma nominal.

De acordo com a análise dos dados, a posse em Libras acontece por meio de: (i) uso de pronomes; (ii) do sinal PRÓPRIO e (iii) por justaposição. Essas três estratégias estabelecem uma relação de posse entre um sintagma nominal possuidor e um sintagma nominal possuído.

A pesquisa permitiu identificar pronomes possessivos com a configuração de mão em $B$, com a configuração de mão em $P$ e com a configuração de mão em IX, que apresentam uma distribuição distinta em relação às pessoas do discurso. O pronome possessivo com a configuração de mão em B está relacionado apenas à primeira pessoa do singular. Os pronomes com a configuração de mão em $\mathrm{P}$ e em IX apresentam uma distribuição mais ampla. Sugerimos que o pronome possessivo com a configuração de mão em $P$ não é usado para primeira pessoa do plural e que o pronome possessivo com a configuração de mão em IX é usado para todas as pessoas do discurso, embora mais estudos sejam necessários para uma generalização mais consistente.

Sugerimos também que os pronomes possessivos possuem um comportamento direcional, assim como os sinais de apontamento e os verbos de indicação, de maneira a indicar o referente possuidor. 
Ainda sobre os pronomes, apresentamos alguns padrões articulatórios, como o número de mãos, repetição e posição do pronome em relação referente possuído. Os dados apresentam os pronomes com um padrão de articulação monomanual e posposto, em sua maioria. Os pronomes com a configuração de mão em $\mathrm{B}$ e em $\mathrm{P}$ são repetidos, em sua maioria, enquanto os pronomes com a configuração de mão em IX, todos, foram articulados sem repetição. Na pesquisa, não estivemos atentos a outras questões, como a existência de sentenças topicalizadas e questões como intensidade, que podem ter influenciado os padrões de manifestação observados.

O sinal PRÓPRIO mostrou-se um item lexical relacionado à posse em Libras. Nas sentenças analisadas, esse sinal foi articulado posposto ao referente possuído e preposto ao referente possuidor, em sua maioria, e, em um dos dados, o sinal PRÓPRIO foi articulado após a justaposição entre possuído e possuidor. Sugerimos também a necessidade de mais pesquisas para descrevermos, a fundo, a semântica deste sinal relacionado à posse e também seu uso em sentenças com pronomes possessivos. A construção de posse por justaposição, na Libras, acompanha a construção núcleo + modificador, em que o referente possuidor (modificador) é articulado após o referente possuído (núcleo). Nesse sentido, a construção de posse por justaposição segue o padrão possuído + possuidor.

Ao disponibilizar uma descrição sobre o sistema de posse na Libras, este estudo, mesmo com suas limitações, contribui para conhecermos mais sobre esse domínio funcional em uma perspectiva tipológica. Este estudo contribui também para o fortalecimento da linguística da Libras e das línguas de sinais, valorizando-as. Além disso, disponibilizamos conhecimento sobre um domínio gramatical da Libras, o que contribui para a implementação de políticas envolvendo áreas aplicadas. 


\section{Referências}

BALDI, Philip; NUTI, Andrea. Possession. In: BALDI, Philip; NUTI, Andrea (org.). New Perspectives on Historical Latin Syntax 3. Constituent Syntax: Quantification, Numerals, Possession, Anaphora. Berlin: De Gruyter Mouton, 2010. p. 239-388.

BERENZ, Norine. Person and Dêixis in Brazilian Sign Language. 1996. Ph.D. (Doctor of Philosophy in Linguistics) - Graduate Division, University of California., Berkeley, 1996.

EL KHOURI. Estratégias de Expressão de Posse em Libras. 2020.

Dissertação (Mestrado em Letras) - Câmpus de Porto Nacional, Universidade Federal do Tocantins, Porto Nacional - Tocantins, 2020. FELIPE, Tanya Amara. Libras em Contexto. Rio de Janeiro: Wal Print Gráfica e Editora, 2007.

FERREIRA, Lucinda. Por uma Gramática de Língua de Sinais. Rio de Janeiro: Editora Tempo Brasileiro/UFRJ, 1995.

GABAS JÚNIOR, Nilson. Linguística Histórica. In: MUSSALIM, Fernanda; BENTES, Anna Christina. Introdução à linguística: domínios e fronteiras. Volume 1. São Paulo: Cortez, 8. ed., 2000. p. 77-104.

HERSLUND, Michael; BARON, Irène. Introduction: Dimensions of possession. In: BARON, Irène; HERSLUND, Michael; SORENSEN, Finn. (org). TSL. Philadelphia: John Benjamins. 2001. v. 47, p. 1-25.

JOHNSTON, Trevor; SCHEMBRI, Adam. Australian Sign Language (Auslan): An Introduction to Sign Language Linguistics. Cambridge: Cambridge University Press, 2006. 323p.

LIDDELL, Scott K. Grammar, gesture and meaning in american sign language. Cambridge: Cambridge University Press, 2003.

LIDDELL, Scott K.; JOHNSON, Robert E. American Sign Language: The Phonological Base. Sign Language Studies, Washington, v. 64, fall, p. 195-277, 1989. 
NICHOLS, Johanna. Head-marking and dependent-marking grammar. Language, Washington, v. 62, n. 1, p. 56-119, march, 1986. PFAU, Roland; STEINBACH, Markus; WOLL, Bencie. Sign Language. An International Handbook. Berlin/Boston: Walter de Gruyter, 2012. QUADROS, Ronice Muller; KARNOPP, Lodenir Becker. Língua de Sinais Brasileira: Estudos Linguísticos - Porto Alegre: Artmed, 2004. QUER, Josep; CECCHETTO, Carlo; DONATI, Caterina; GERACI, Carlo; KELEPIR, Meltem; PFAU, Roland; STEINBACH, Markus. A Guide to Sign Language Grammar Writing. Berlin/Boston: Walter de Gruyter GmbH, 2017.

SANCHEZ-MENDES, Luciana; SEGALA, Rimar Ramalho; XAVIER, André Nogueira. O papel da (re)duplicação na expressão de pluracionalidade em Libras. Revista Letras, Curitiba, v. 96, n. 1, jul./dez., p. 487-508, 2017.

SANCHEZ-MENDES, Luciana; XAVIER, André Nogueira. A expressão de pluracionalidade em Libras. Estudos Linguísticos, São Paulo, v. 45, n.1, p. 292-304, 2016.

SEILER, Hansjakob. The operational basis of possession: A dimensional approach revisited. In: BARON, I.; HERSLUND, M.; SORENSEN, F. (org). Dimensions of possession. TSL. Philadelphia: John Benjamins. 2001. v. 47, p. $27-40$.

STENZEL, Kristine. Marking 'possessive' relations in the Vaupés: areal features and diffusion. Papers presented at the $8^{\text {th }}$ Meeting of Association for Linguistic Typology. Berkeley, CA, 2009.

ZESHAN, Ulrike. Indo-Pakistani Sign Language Grammar: A Typological Outline. Sign Language Studies, Washington, v. 3, n. 2. Gallaudet University Press, Winter 2003. p. 157-212.

ZESHAN, Ulrike; PERNISS, Pamela. Possessive and Existential constructions in sign languages. Nijmegen: Ishara Press, 2008. 